\title{
Fundamental Frequency of Laminated Composite Thick Spherical Shells
}

\author{
Mohammad Zannon \\ Correspondence: Department of Mathematics, Tafila Technical University, Tafila, Jordan. E-mail: \\ zanno1ms@gmail.com
}

Received: August 10, 2018

Accepted: November 25, 2018 Online Published: January 22, 2019

doi:10.5539/jmr.v11n1p57

URL: https://doi.org/10.5539/jmr.v11n1p57

\begin{abstract}
In this study, we apply third-order shear deformation thick shell theory to analytically derive the frequency characteristics of the free vibration of thick spherical laminated composite shells. The equations of motion are derived using Hamilton's principle of minimum energy and on the basis of the relationships between forces, moments, and stress displacements in the shell.

We confirm the derived equations and analytical results through the finite element technique by using the well-known software packages MATLAB and ANSYS. We consider the fundamental natural frequencies and the mode shapes of simply supported spherical cross-ply $(0,90),(0,90,0)$, and $(0,90,90,0)$ laminated composite shells. Then, to increase accuracy and decrease calculation efforts, we compare the results obtained through classical theory and first-order shear deformation theory.
\end{abstract}

Keywords: equations of motion, free vibration, Hamilton's principle, laminated composite, natural frequency, spherical shell

\section{Introduction}

Spherical shells are used mainly for the storage of gas, petrol, liquids, chemicals, and grains. Moreover, they are applied in engineering and transportation, particularly in the structures of motor vehicles, ships, and aircraft (Birman \& Byrd, 2007; Koizumi, 1997; Carrera, 2003)

Over the past four decades, the use of spherical laminated composite shells in many engineering fields has rapidly expanded given the better strength and stiffness-to-weight ratios of these materials than those of metallic materials (Zannon, Al-Shutnawi \& Alrabaiah, 2015; Zhong \& Ertao, 2008; Nguyen, Sab, \& Bonnet, 2007). Composite spheres are the main components of modern airspace and submarine structures and are increasingly used in automotive and biomedical engineering.

Most current theoretical foundations are based on Kirchhoff-Love theory of classical two dimensional bending thin plates and Mindlin-Reissner plate theory of shear deformation and rotary inertia due to rotation. The present work extends previously proposed theories by accounting for the terms related to the effect of midsurface thickness.

Shell structures can be classified on the basis of their curvatures: plates without curvature; cylindrical with one curvature; spherical with two equal curvatures; and conical with zero curvature and one curvature that linearly changes with axial length (Qatu, Zannon, \& Mainuddin, 2013; Zannon, Al-Shutnawi, \& Alrabaiah, 2015; Reddy, 1984; Zannon\& Alrabaiah, 2016). Lamb (1882) examined the free vibration of a complete spherical shell for the first time (Baker, 1961). A detailed treatment by Baker (Baker, 1961) and Silbiger (Silbiger, 1962) revealed numerous interesting features that served as a test case for shell elements in the third-order shear deformation of thick shell theory. Kalnins (Kalnins, 1964)and Qusai (Jebur,2008) investigated the vibration of thick spherical shells. Thin spherical shells have been studied by several researchers (Baker, 1961; Kalnins, 1964; Lamb, 1882; Silbiger, 1962; Jebur, 2008). The dynamic axial compression of glass-polyester composite semispherical shells was studied by Lamb (Lamb, 1882). Heated fluid-filled spherical composite shells were studied by (Baker, 1961; Kalnins, 1964; Lamb, 1882; Silbiger, 1962). 


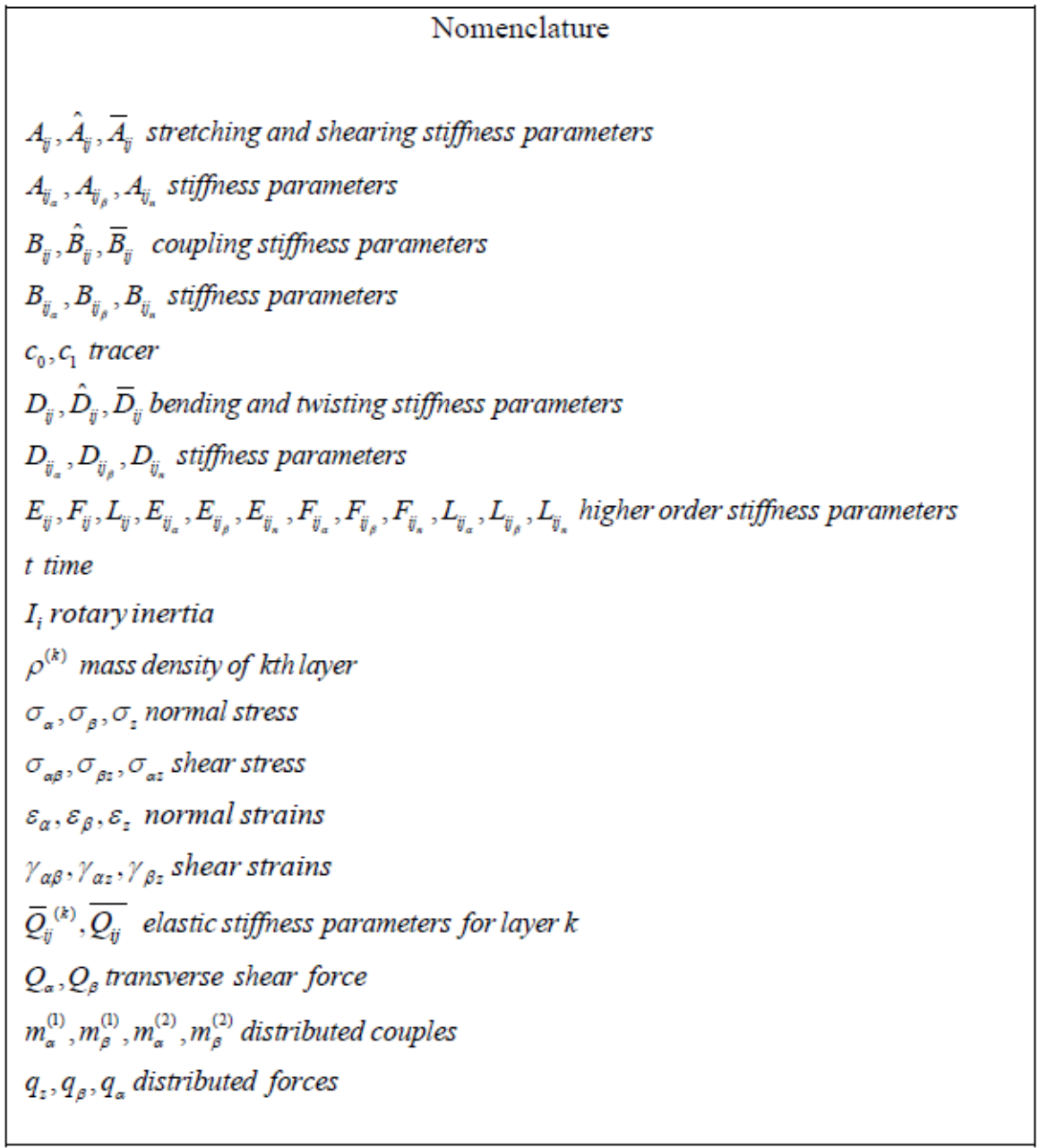

This work aims to provide an analytical solution to the frequency characteristics of the free vibration of thick spherical laminated composite shells (Reddy, 1984). The general formulation of the classical bending theory of shells is based on early works on shell vibration (Zannon \& Qatu, 2014; Kapania,1989;Noor\&Burton,1990).

System discretization yields a standard linear eigenvalue problem involving two independent variables(Baker,1961;Kalnins,1964;Lamb,1882;Silbiger,1962;Jebur,2008). The complete assessment of modal shapes that correspond to the natural frequencies of structures is thus computed.

The governing motion equations in this work comprise a set of eight two-dimensional partial differential equations with variable coefficients, and the system of second-order linear partial differential equations is solved (Qatu,Zannon,\&Mainuddin,2013; Zannon,Al-Shutnawi,\&Alrabaiah ,2015)

\section{Basic Governing Equations}

Spherical shells are special cases of revolving shells. A circular arc, rather than a straight line, revolves around an axis to generate the surface of a spherical shell. A close sphere will result if the circular arc is half a circle and the axis of rotation is the diameter of the circle.

This work focuses on closed or deep spherical shells composed of layers with spherical orthotropic characteristics (Zhong\& Ertao,2008;Nguyen,Sab,\&Bonnet,2007).

The literature on closed composite spherical shells is limited. This limitation may be attributed to the difficulty of producing laminates that form closed spheres.

The spherical shell equation can be obtained by deriving and substituting the appropriate Lamé parameters of spherical shells in general shell equations (Qatu, Zannon, \& Mainuddin, 2013),( Zhong \& Ertao,2008;Nguyen,Sab,\&Bonnet,2007). Considering Figure 1, the fundamental form can be written as

$$
(d s)^{2}=R^{2}(\mathrm{~d} \varphi)^{2}+R^{2} \sin ^{2}(\varphi)(\mathrm{d} \theta)^{2}
$$


which yields the following Lamé parameters and radii of curvature

$$
A=R, B=R \sin (\varphi), \mathrm{R}_{\varphi}=R_{\theta}=R
$$

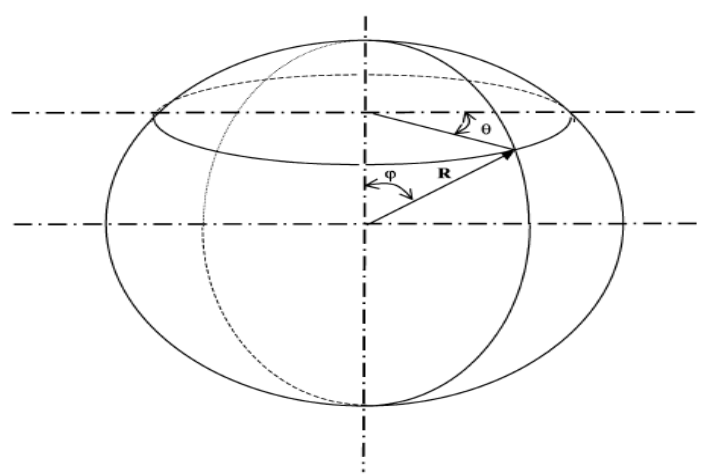

Figure 1. A Closed spherical shell (Qatu,2002)

The governing differential equations, the strain energy due to load, kinetic energy, and formulations of the general dynamic problem are derived on the basis of Hamilton's principle (Qatu,Zannon,\&Mainuddin,2013),(Qatu,2002;Zhong\& Ertao,2008;Nguyen,Sab,\&Bonnet,2007).

In the present work, we consider a thick shell with a value of thickness that is lower than the values of other shell parameters, such as width, shape length, and curvature radii, which is usually taken as (1/10) of its measure. The vibrational analysis of thick shells often includes rotational inertia factors and shear deformation (Koizumi, 1997; Carrera, 2003). In shell deformation theory, middle plane displacements are stretched in terms of shell thickness and can utilize first- or-higher order approximation. Therefore, three-dimensional elasticity theories are reduced to two-dimensional theories by ignoring the normal strain over other strain components that act on the plane parallel to the middle surface(Jebur,2008),(Zannon, Al-Shutnawi,\&Alrabaiah ,2015), (Koizumi, 1997; Carrera, 2003). Generally, such assumptions can be justified outside of the neighborhood of highly rigorous force. Thus, normal strains acting upon the plane parallel to the middle surface are not negligible $\left(\varepsilon_{z} \neq 0\right)$.

On the basis of the third-order shear deformation shell theory and applying the displacement field (Qatu,Zannon,\& Mainuddin,2013;Zannon,Al-Shutnawi\&Alrabaiah ,2015),

$$
\left.\begin{array}{l}
u(\alpha, \beta, z)=u_{0}(\alpha, \beta)+z \quad \psi_{\alpha}(\alpha, \beta)+z^{3} \varphi_{\alpha}(\alpha, \beta) \\
v(\alpha, \beta, z)=v_{0}(\alpha, \beta)+z \quad \psi_{\beta}(\alpha, \beta)+z^{3} \varphi_{\beta}(\alpha, \beta) \\
w(\alpha, \beta, z)=w_{0}(\alpha, \beta)+z \quad \psi_{z}(\alpha, \beta)
\end{array}\right\}
$$

The fundamental equations of thick spherical shells will be derived by substituting the Lamé parameters and radii of curvature derived with Eq. (1) into the general equations (Qatu,Zannon,\& Mainuddin,2013;Zannon,Al-Shutnawi\&Alrabaiah ,2015), by using the third-order shear deformation of thick shell theory (Baker,1961;Kalnins,1964;Lamb,1882),( Koizumi, 1997; Carrera, 2003).

Substituting Eq. (1) into the general equations given in [6-7] yields the midsurface normal, in-plane, and shear strains for a thick spherical shell:

$$
\left.\begin{array}{ll}
\varepsilon_{0 \varphi}=\frac{1}{R} \frac{\partial u_{0}}{\partial \varphi}+\frac{w_{0}}{R}, & \varepsilon_{0 \theta}=\frac{1}{R \sin (\varphi)} \frac{\partial v_{0}}{\partial \theta}+\frac{u_{0} \cot (\varphi)}{R}+\frac{w_{0}}{R}, \\
\varepsilon_{0 \varphi \theta}=\frac{1}{R} \frac{\partial v_{0}}{\partial \varphi}, & \varepsilon_{0 \theta \varphi}=\frac{1}{R \sin (\varphi)} \frac{\partial u_{0}}{\partial \theta}-\frac{v_{0}}{R} \cot (\varphi), \\
\gamma_{0 \varphi z}=\frac{1}{R} \frac{\partial w_{0}}{\partial \varphi}-\frac{u_{0}}{R}+\psi_{\varphi}, & \gamma_{0 \theta=}=\frac{1}{R \sin (\varphi)} \frac{\partial w_{0}}{\partial \theta}-\frac{v_{0}}{R}+\psi_{\varphi} .
\end{array}\right\}
$$

The curvature and twist changes of the shells can be written as 


$$
\begin{aligned}
& \kappa_{\varphi}^{(1)}=\frac{1}{R} \frac{\partial \psi_{\alpha}}{\partial \varphi}+\frac{\psi_{z}}{R}, \quad \kappa_{\alpha}^{(2)}=\frac{1}{R} \frac{\partial \phi_{\varphi}}{\partial \varphi}, \\
& \kappa_{\alpha \varphi}^{(1)}=\frac{1}{R} \frac{\partial \psi_{\beta}}{\partial \varphi}, \quad \kappa_{\varphi \theta}^{(2)}=\frac{1}{R} \frac{\partial \phi_{\theta}}{\partial \varphi}, \\
& \kappa_{\theta \varphi}^{(1)}=\frac{1}{R \sin (\varphi)} \frac{\partial \psi_{\varphi}}{\partial \theta}-\frac{\psi_{\theta}}{R} \cot (\varphi), \kappa_{\theta \varphi}^{(2)}=\frac{1}{R \sin (\varphi)} \frac{\partial \phi_{\varphi}}{\partial \theta}-\frac{\phi_{\theta}}{R} \cot (\varphi), \\
& \kappa_{\theta}^{(1)}=\frac{1}{R} \frac{\partial \psi_{\theta}}{\partial \theta}+\frac{\psi_{\varphi}}{R} \cot (\varphi)+\frac{\psi_{z}}{R}, \quad \kappa_{\theta}^{(2)}=\frac{1}{R} \frac{\partial \phi_{\theta}}{\partial \theta}+\frac{\phi_{\varphi}}{R} \cot (\varphi) . \\
& G^{(1)}=\frac{1}{R} \frac{\partial \psi_{z}}{\partial \varphi}+2 \phi_{\varphi}, E^{(1)}=\frac{1}{R \sin (\varphi)} \frac{\partial \psi_{z}}{\partial \beta}+2 \phi_{\theta} \\
& G^{(2)}=\frac{\phi_{\theta}}{R}, E^{(2)}=\frac{\phi_{\theta}}{R} .
\end{aligned}
$$

The equation of motion for free vibration analysis is obtained using Hamilton's principle (Jebur,2008),(Zannon\& Alrabaiah,2016;Birman\&Byrd,2007).

$$
\begin{aligned}
& \mathrm{R} \cos (\varphi) N_{\varphi}-\mathrm{R} \cos (\varphi) N_{\theta}+\frac{\partial}{\partial \theta}\left(\mathrm{R} N_{\beta \varphi}\right)+\mathrm{R} \sin (\varphi) Q_{\varphi}+\mathrm{R}^{2} \sin (\varphi) q_{\varphi} \\
& =\mathrm{R}^{2} \sin (\varphi)\left(\bar{I}_{1} \ddot{u}_{0}+\bar{I}_{2} \ddot{\psi}_{\varphi}\right) \text {. } \\
& \mathrm{R} \cos (\varphi) N_{\theta \beta}+\mathrm{R} \cos (\varphi) N_{\theta \varphi}+\frac{\partial}{\partial \theta}\left(\mathrm{R} N_{\theta}\right)+\mathrm{R} \sin (\varphi) Q_{\theta}+\mathrm{R}^{2} \sin (\varphi) q_{\theta} \\
& =\mathrm{R}^{2} \sin (\varphi)\left(\bar{I}_{1} \ddot{v}_{0}+\bar{I}_{2} \ddot{\psi}_{\beta}\right) \text {. } \\
& \mathrm{R} \cos (\varphi) Q_{\varphi}+\frac{\partial}{\partial \theta}\left(\mathrm{R} Q_{\theta}\right)-\mathrm{R} \sin (\varphi)\left(N_{\varphi}+N_{\theta}\right)+\mathrm{R}^{2} \sin (\varphi) q_{n}=\mathrm{R}^{2} \sin (\varphi)\left(\bar{I}_{1} \ddot{w}_{0}\right) . \\
& \mathrm{R} \cos (\varphi) M_{\varphi}^{(1)}-R \cos (\varphi) M_{\theta}^{(1)}+\frac{\partial}{\partial \theta}\left(\mathrm{R} M_{\varphi \varphi}^{(1)}\right)-\mathrm{R}^{2} \sin (\varphi) Q_{\varphi}+\mathrm{R}^{2} \sin (\varphi) m_{\varphi}^{(1)} \\
& =\mathrm{R}^{2} \sin (\varphi)\left(\bar{I}_{2} \ddot{u}_{0}+\bar{I}_{3} \ddot{\psi}_{\varphi}\right) . \\
& \frac{\partial}{\partial \theta}\left(\mathrm{R} M_{\theta}^{(1)}\right)+\mathrm{R} \cos (\varphi) M_{\varphi \theta}^{(1)}+R \cos (\varphi) M_{\theta \varphi}^{(1)}-\mathrm{R}^{2} \sin (\varphi) Q_{\theta}+\mathrm{R}^{2} \sin (\varphi) m_{\theta}^{(1)} \\
& =\mathrm{R}^{2} \sin (\varphi)\left(\bar{I}_{2} \ddot{v}_{0}+\bar{I}_{3} \ddot{\psi}_{\beta}\right) \text {. } \\
& \mathrm{R} \cos (\varphi) P_{\varphi}^{(1)}+\frac{\partial}{\partial \theta}\left(\mathrm{R} P_{\theta}^{(1)}\right)-\mathrm{R}^{2} \sin (\varphi)\left(N_{z}+\frac{M_{\varphi}^{(1)}}{R}+\frac{M_{\theta}^{(1)}}{R}\right)+\mathrm{R}^{2} \sin (\varphi) m_{z}=\mathrm{R}^{2} \sin (\varphi)\left(\bar{I}_{3} \ddot{\psi}_{z}\right) . \\
& \mathrm{R} \cos (\varphi) M_{\varphi}^{(2)}-R \cos (\varphi) M_{\theta}^{(2)}+\frac{\partial}{\partial \theta}\left(\mathrm{R} M_{\theta \varphi}^{(2)}\right)-2 \mathrm{R}^{2} \sin (\varphi) P_{\varphi}^{(1)}+\mathrm{R}^{2} \sin (\varphi) m_{\varphi}^{(2)} \\
& =\mathrm{R}^{2} \sin (\varphi)\left(\bar{I}_{3} \ddot{u}_{0}+\bar{I}_{4} \ddot{\varphi}_{\varphi}\right) \text {. } \\
& \left.\frac{\partial}{\partial \theta}\left(\mathrm{R} M_{\theta}^{(2)}\right)+\mathrm{R} \cos (\varphi) M_{\varphi \theta}^{(2)}\right)-\left(\mathrm{R} \sin (\varphi) P_{\theta}^{(2)}+\mathrm{R} \sin (\varphi) P_{\varphi}^{(2)}+2 \mathrm{R}^{2} \sin (\varphi) P_{\theta}^{(1)}\right)+\mathrm{R}^{2} \sin (\varphi) m_{\theta}^{(2)} \\
& =\mathrm{R}^{2} \sin (\varphi)\left(\bar{I}_{3} \ddot{v}_{0}+\bar{I}_{4} \ddot{\varphi}_{\theta}\right) \\
& \text { where } \bar{I}_{i}=\left(I_{i}+I_{i+1}\left(\frac{2}{R}\right)+\frac{I_{i+2}}{R^{2}}\right), \quad \forall i=1,2,3,4
\end{aligned}
$$

\section{Numerical Results and Discussions}

The analytical solution developed using the third-order shear deformation theory is employed to validate its applicability in the dynamic analysis of symmetric and nonsymmetric cross-ply spherical laminated shells. Moreover, it is compared with other theories used by other researchers, such as FSDT(Qatu,Zannon,\&Mainuddin,2013;Zannon, Al-Shutnawi,\& Alrabaiah 2015), (Koizumi,1997;Carrera,2003).

In this respect, the fundamental natural frequency is obtained for thick shells fabricated with $(0,90,0),(0,90)$, and 
$(0,90,90,0)$ composites and with the radius-to-side length ratios $\frac{a}{R}=0.05,0.1,0.2$ and $\frac{a}{h}=10$. The material property characteristics of the considered structures are listed in Table 1. Moreover the results obtained by the present method are in good agreement with the existing theory and given in Tables 2-4.

Table 1. Physical parameters used in the analysis of the free vibration of spherical shells

\begin{tabular}{c|c|c|c|c|c|c}
\hline$E_{1}$ & $E_{2}=E_{3}$ & $G_{12}=G_{13}$ & $G_{23}$ & $v_{12}=v_{13}$ & $v_{23}$ & $\rho$ \\
\hline $2 \times 10^{6} \mathrm{pi}$ & $1 \times 10^{6} \mathrm{pi}$ & $0.5 \times 10^{6} \mathrm{pi}$ & $0.2 \times 10^{6} \mathrm{pi}$ & 0.24 & 0 & 1 \\
\hline
\end{tabular}

Table 2. Nondimensional fundamental frequency parameters $\Omega_{i}=\omega_{i} a^{2} \sqrt{\rho E_{2} / \mathrm{h}^{2}}$ of simply supported symmetric $[0 / 90 / 90 / 0]$ orthotropic spherical shells with $a / h=10$

\begin{tabular}{cccc}
\hline$\frac{a}{R}$ & FEM & FSDT & TSDTZ \\
(Koizumi,1997;Carrera,2003) & (Qatu,2002Zhong\&Ertao,2008) & (Present) \\
\hline 0.05 & 11.023 & 11.798 & 11.7828 \\
0.1 & 11.024 & 11.840 & 11.7828 \\
0.2 & 11.683 & 12.007 & 11.9702 \\
\hline
\end{tabular}

Table 3. Nondimensional fundamental frequency parameters $\Omega_{i}=\omega_{i} a^{2} \sqrt{\rho E_{2} / \mathrm{h}^{2}}$ of simply supported antisymmetric $[0 / 90 / 0]$ orthotropic spherical shells with $a / h=10$

\begin{tabular}{cccc}
\hline$\frac{a}{R}$ & FEM & FSDT & TSDTZ \\
(Present)
\end{tabular}

Table 4. Nondimensional fundamental frequency parameters $\Omega_{i}=\omega_{i} a^{2} \sqrt{\rho E_{2} / \mathrm{h}^{2}}$ of simply supported two-ply [0/90] orthotropic spherical shells with $a / h=10$

\begin{tabular}{cccc}
\hline$a$ & FEM & FSDT & TSDTZ \\
$R$ & (Koizumi,1997;Carrera,2003) & (Qatu,2002Zhong\&Ertao,2008) & (Present) \\
\hline 0.05 & 8.201 & 8.921 & 8.9893 \\
0.1 & 8.254 & 8.984 & 9.0504 \\
0.2 & 8.872 & 9.230 & 9.290 \\
\hline
\end{tabular}

Fig. 2 shows that the frequency parameter changes $\Omega_{i}$ with the ratio $a / R$. This behavior indicates that the fundamental natural frequency of $(0,90,0)$ and $(0,90,90,0)$ composites increases as $a / R$ increases.

Notably, the fundamental frequency of symmetric shells is greater than that of antisymmetric ones.
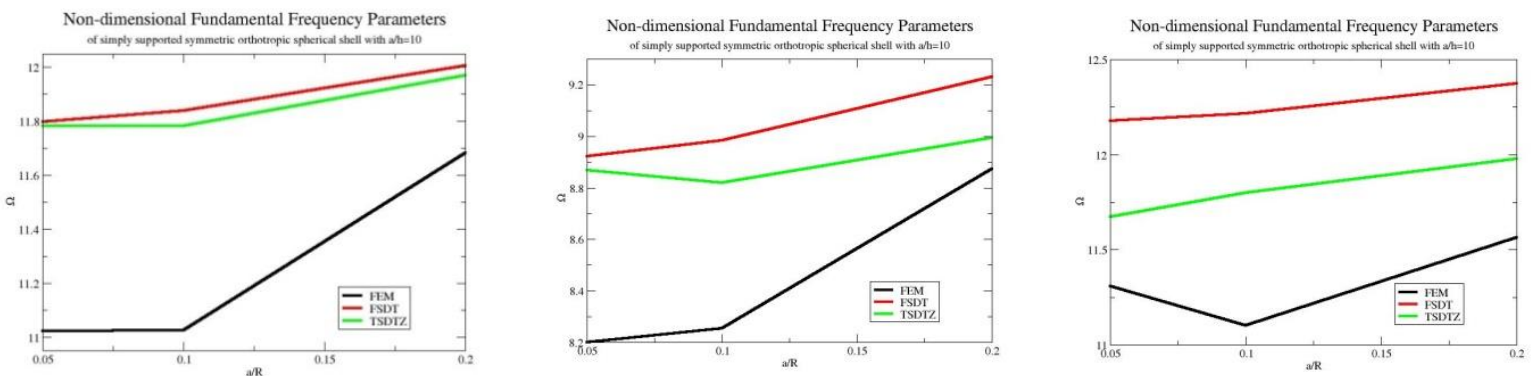

The first three mode shapes for the spherical shell of composite type $(0,90)$ are shown in the following figure. 


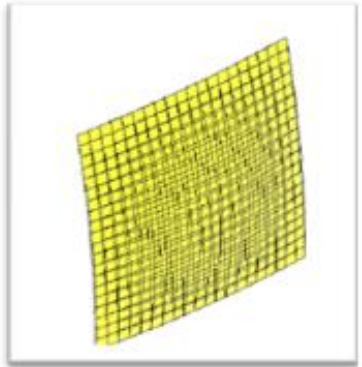

1. First mode shape

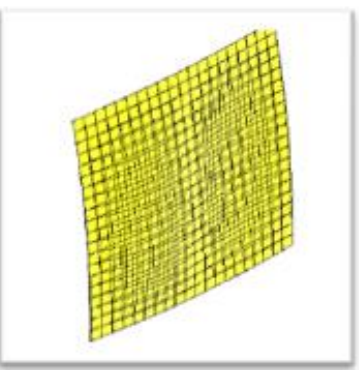

2. Second Mode shape

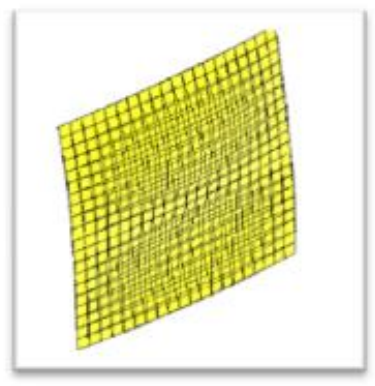

3. Third mode shape

\section{Conclusion}

A versatile and accurate third-order shear deformation shell theory for the free vibration of thick spherical laminated composite shells is presented. The present results are compared with the three-dimensional theory of elasticity and first-order shear deformation theory available in the literature. The third-order shear deformation theory for thick laminated shells is applied to solve for the free vibrational characteristics of thick spherical shells with simply supported boundary conditions and cross-ply laminates.

The results show that the natural frequency of $(0,90$, and 0$)$ and $(0,90,90,0)$ shells tends to increase if the value of the radius is increased to the value of the side length. On the other hand, the natural frequency of $(0,90)$ and $(0,90,90,0)$ decreases as the radius-to-side ratio increases.

The presented theory will help numerous researchers to further develop theories for the complex geometry of shell deformation for future applications

\section{References}

Baker, W. E. (1961).Axisymmetric Modes of Vibration of Thin Spherical Shells. Journal of Acoustic Society of America, 33, 1749-1758. https://doi.org/10.1121/1.1908562

Birman, V., \& Byrd, L. W. (2007). Modeling and analysis of functionally graded materials and structures. Applied Mechanics Reviews, 60(5), 195-216. https://doi.org/10.1115/1.2777164

Carrera, E. (2003). Theories and finite elements for multilayered plates and shells: a unified compact formulation with numerical assessment and benchmarking. Archives of Computational Methods in Engineering, 10, 215-296. https://doi.org/10.1007/BF02736224

Jebur, Q. H. (2008). Dynamic Analysis of Thin Composite Cylindrical and Spherical Shells. Al-Khwarizmi Engineering Journal, 4(2), 69- 75.

Kalnins, A. (1964). Effect of Bending on Vibration of Spherical Shells. Journal of Acoustic Society of America, 36, 7481. https://doi.org/10.1121/1.1918916

Kapania, P. K. (1989). Review on the Analysis of Laminated Shells. Journal of Pressure Vessel Technology, 111, 88-96. https://doi.org/10.1115/1.3265662

Koizumi, M. (1997).Use of Composites Multi-Phased and Functionally Graded Materials. Fgm activities in japan. Composites Part B: Engineering, 28(1-2), 1-4. https://doi.org/10.1016/S1359-8368(96)00016-9

Lamb, H. (1882).On the Vibrations of a Spherical Shell. Procedures of the London Mathematical Society, 14, 50-56. https://doi.org/10.1112/plms/s1-14.1.50

Nguyen, T. K., Sab, K., \& Bonnet, G. (2007). Shear correction factors for functionally graded plates. Mechanics of Advanced Materials and Structures, 14(8), 567-575. https://doi.org/10.1080/15376490701672575

Noor, A. K., \&Burton, W. S. (1990). Assessment of Computational Models for Multilayered Composite Shells. Applied Mechanics Reviews, 43(4), 67- 97. https://doi.org/10.1115/1.3119162

Qatu, M. S. (2002). Recent Research Advances in the Dynamic Behavior of Shells: 1989-2000. Part 1: Laminated Composite Shells. Applied Mechanics Reviews, 55(4), 325-350. https://doi.org/10.1115/1.1483079

Qatu, M. S. (2004).Vibration of Laminated Shells and Plates.Elsevier, Amsterdam.

Qatu, M., Zannon, M., \& Mainuddin, G. (2013). Application of Laminated Composite Materials in Vehicle Design: Theories and Analyses of Composite Shells. SAE Int. J. Passeng. Cars - Mech. Syst, 6(2), 1347-1353. https://doi.org/10.4271/2013-01-1989 
Reddy, J. N. (1984). Exact Solutions of Moderately Thick Laminated Shells. Journal of Engineering Mechanics, 110(5), 794-809. https://doi.org/10.1061/(ASCE)0733-9399(1984)110:5(794)

Reddy, J. N., \& Lium, C. F. (1985). A Higher-Order Shear Deformation Theory of Laminated Elastic Shells. International Journal of Eng, 23(3). https://doi.org/10.1016/0020-7225(85)90051-5

Silbiger, A. (1962). Nonaxisymmetric Modes of Vibration of Thin Spherical Shells. Journal of Acoustic Society of America, 34, 862. https://doi.org/10.1121/1.1918210

Zannon, M., \& Alrabaiah, H. (2016). Mathematical Formulation of Laminated Composite Thick Conical Shells. Journal of Mathematics Research, 8(4). https://doi.org/10.5539/jmr.v8n4p166

Zannon, M., \& Qatu, M. (2014). Free Vibration Analysis of Thick Cylindrical Composite Shells Using Higher Order Shear Deformation Theory. International Journal of Engineering Research and Management (IJERM), 1(7).

Zannon, M., \& Qatu, M. (2014). Mathematical Modeling of Transverse Shear Deformation Thick Shell Theory. International Journal of Engineering Research and Management (IJERM), 1(7).

Zannon, M., Al-Shutnawi, B., \& Alrabaiah, H. (2015). Theories and Analyses Thick Hyperbolic Paraboloidal Composite Shells. American Journal of Computational Mathematics, 5, 80-85. https://doi.org/10.4236/ajcm.2015.52006

Zhong, Z., \& Ertao, S. (2008).Closed-form solutions of three-dimensional functionally graded plates. Mechanics of Advanced Materials and Structures, 15(5), 355-363. https://doi.org/10.1080/15376490801977528

\section{Copyrights}

Copyright for this article is retained by the author(s), with first publication rights granted to the journal.

This is an open-access article distributed under the terms and conditions of the Creative Commons Attribution license (http://creativecommons.org/licenses/by/4.0/). 